\title{
Demonstrating impact: a possible approach for the LIS researcher
}

\author{
Andrew K. Shenton
}

\begin{abstract}
For many years, research has been judged according to the number of citations it attracts. However, this criterion may be criticised for paying no attention to differences in the nature of individual citations. This article shows how researchers can produce an impact continuum, with one pole highlighting situations where their work is integral to a later study and the other scenarios where it is only peripheral. The continuum presented here suggests ten categories of use and examples from the author's own work are given as illustrations. The paper also outlines problems associated with the continuum. These include subjectivity in the placement of the categories and the potential difficulty of determining how far a particular study has actually influenced the thinking of a later researcher. Nevertheless, there are clear ways in which the structure may be helpful to readers seeking to highlight their research impact through typologies and case studies.
\end{abstract}

\section{Introduction: the nature of the problem}

The task of assessing the impact of their work is a key challenge for many serious researchers today. It is a particularly important task for a higher doctorate candidate as university regulations are likely to require proof of such impact if the award is to be made. The applicant may believe that showing impact is also integral to the achievement of a related purpose, such as establishing the calibre or authority of their work. In summarising the criteria which must be met by higher doctoral submissions, Barnes (2013) concludes that:

the focus is predominantly on a high standard of scholarly research, high quality, high impact publications and international research standing.

(Barnes, 2013, 16-17)

\section{Author}

Andrew K. Shenton is an independent researcher who works part-time in a high school in the north-east of England.

Email: 96shentona@monkseaton.org.uk

Received 21 July 2014

Accepted 08 December 2014 
It is clear from an earlier table in Barnes' report that, in this context, impact relates to that of the journals in which the work appears, rather than that of individual papers, so the higher doctoral candidate may give special emphasis to journal impact statistics. Another option, though, lies in the applicant concentrating their interest directly on their actual work. Conventional wisdom maintains that the more citations a paper attracts, the greater must be its impact. For Harzing $(2011,3)$, the appeal of such counts arises from the fact that numbers of citations represent "the collective 'verdict' of the market". Even here, though, bland statistics give little insight into the degree and the nature of the use that has been made of the paper involved.

Nearly twenty years ago, Wilson $(1996,90)$ argued that citation data constituted the "commonest method of assessing impact", and today tools such as Web of Science, Google Scholar and Publish or Perish render it easier than ever before to collect figures pertaining to the number of occasions on which the individual's work has been cited. Comparative data may also be gathered with little effort, in relation, for example, to the most heavily cited papers in a particular journal, and, if these data can be used to show the researcher in a favourable light, such figures may be quoted in the process of applying for the award of a higher doctorate. Yet, as Sarli, Dubinsky and Holmes (2010) point out, citation statistics present only a partial picture of the value of a study. The authors provide a critical insight into the shortcomings of citation analysis in the medical sphere and conclude that such an analysis:

does not reveal whether research findings result in new diagnostic applications, a new standard of care, changes in health care policy, or improvement in public health. In short, citation analysis does not provide a full narrative of meaningful health outcomes.

(Sarli, Dubinsky and Holmes, 2010, 22)

Very often, many of the references to a certain paper are found merely in reviews of the literature and the individual is just one of dozens of commentators cited. In these circumstances, we may well ask, "Just how much impact has that person's work really made?" It may well be accepted by the citing authors that the paper forms a worthwhile part of the established knowledge base but - in themselves literature reviews are scant evidence that the source material has been of fundamental value to the author using it. The real challenge for the individual lies in identifying situations where their work has been employed in the creation of something new, instead of simply noting the number of instances of citation - a figure that is bound to include cases where their work has merely been reported.

\section{The need to demonstrate research impact beyond higher doctoral situations}

This article is based on my recent experiences of preparing a submission for a higher doctorate at Northumbria University. The article is not, however, aimed solely at applicants for such a degree. It is also intended to be useful to researchers who have no aspirations in this area but who may wish to demonstrate the impact that has been made by their work. They may feel the need to do so for one of a 
range of professional development purposes, such as gaining promotion or advancement, or to secure tenure in an existing position.

All these situations presuppose that it is academics who are intent on demonstrating the impact of their work in the scholarly arena. It is, however, by no means always the case that the use of a past project pertains to new research. Marsh (2010) highlights five areas in which the impact of a study may be felt. Research forms only one of these: practice (especially in terms of industrial and business settings), teaching, public policy and society constitute the remaining four. Readers may find these divisions a useful framework for thinking about the potential impact of their own research, although they are likely to discover that, in their particular circumstances, some of the areas may be more relevant to them than others. In a recent paper (Shenton, 2014), I have attempted to render each of the dimensions somewhat less abstract by presenting a set of pertinent questions derived from Marsh's descriptions of them:

- What evidence is there that the implications of the individual's research have been recognised by others in their own projects leading to the acquisition of further knowledge?

- Have practical issues raised by the work been addressed in fields such as business and industry?

- Can the influence of the papers be seen in education settings, for example through the use of case studies and examples?

- Are there indications that civil servants, politicians or decision-makers in public bodies, institutions or charities have drawn on the research?

- How far has the scholar's work challenged cultural norms and accepted ways of thinking?

Where the researcher's impact has been especially wide ranging, it may be possible for each of Marsh's dimensions to be used as a category within a typology. Some may be broken down into sub-groups. With regard to one of my own areas of interest, information literacy, "teaching" may be divided into individual areas embracing:

- instances in which schools have changed their working practices in order to accommodate the researcher's discoveries;

- examples where, in response to certain principles emerging from one of the investigator's projects, schools have adopted a particular standpoint to underpin their programme of information literacy instruction;

- situations where the inquirer's work has inspired the creation of practical tools for promoting information literacy.

These categories may be arranged in a hierarchical sequence. A logical order may be to move from the strategic at the top down to the practical / operational.

Authors may wish to give thought to the citation statistics issue long before their work is even published. Writers seeking to maximise their readership and the use that is made of their paper may consider publishing in an open access journal. One 
of the greatest advantages of this strategy lies in the fact that the range of readers is likely to be widened; users of traditional journals are often limited to members of academic libraries. For some researchers, there is a moral dimension to the question of dissemination, as well. When a study is publicly financed, it may be argued that the researchers owe it to society at large to make the outputs from their work as widely available as possible and this may best be achieved through open access journals. However, in the eyes of many, open access routes may lack the rigour and credibility of the long-established subscription journals. Certainly, various scandals, such as those reported by Aldhous (2009) and Shaw (2013), in which "hoax" papers have been accepted for publication in open access journals after apparently limited evaluation, scarcely promote confidence in this form of research dissemination.

Issues that link citations and funding may also take other forms. When preparing a proposal for a new project, it may be the case that its authors feel that one of the most effective ways of demonstrating the potential utility of the work lies in discussing how previous related studies carried out in the same discipline have made an impact. In the face of pressures to show the relevance of a particular research project to the "real world", especially at times of financial hardship, there are clear attractions in attending to the areas of practice, teaching, public policy and society which Marsh (2010) highlights. In identifying such impact, researchers may wish to explore the application of altmetrics, which, in recent years, have attracted considerable attention. This term refers to the use of nontraditional impact measures relating to Web-based environments. It embraces mentions in social media and news sources, although the researcher's attention may also be more "local". For example, a piece appearing in an academic journal or professional periodical may be uploaded to the intranet that serves the writer's organisation. Subsequently, logging facilities may be exploited in order, firstly, to discover how many members of the organisational community have accessed the piece and, secondly, to ascertain their identities. If contact is made with these users, then the ways in which the research has been used may also be established. There are several reasons why such an approach may be taken. Senior managers, for example, may be keen to develop evidence-based practice within their organisation and the insights gained may enable them to determine how far such a culture is prevalent, whilst in a research context what can be learnt about the use that is made of outputs such as formative papers may be useful in a future phase of the study.

\section{A grounded research impact continuum}

It is now well accepted that not all citations in a research paper are of comparable value. Indeed, forty years ago, Moravcsik and Murugesan (1975) and Chubin and Moitra (1975) drew a series of distinctions in the ways that source material is used through references. Researchers may be tempted to adopt some of the categories proposed by these writers to show how their own work has been used in different ways. There are, however, certain problems associated with this practice. Such pigeon-holing may encourage the scholar to take a "best fit" approach, with the result that even the citations within a particular category may vary in nature quite significantly. An alternative is to generate categories inductively, based on the 
content of the material under scrutiny. In this approach, types emerge directly from the particular characteristics of the citations under scrutiny. This paper discusses a typology created in this way and orders the categories according to a sliding scale in a manner similar to Chubin and Moitra's (1975) sequence. The source materials are research papers. Citations in comment and review articles are generally beyond the scope of this article.

The following paragraphs outline the form that such a continuum may take. They then explore how the continuum may be used. The work is based on my experiences as a LIS higher doctoral candidate and I make no argument that the structure which I define should be adopted by other researchers. The use made of any individual's publications will vary from one case to another and it would be ill-advised for any reader to seek to understand, in terms of the ten stated categories, how his or her own work has been used. It would be much more sensible for people to develop their own spectrum based on the use that has been made of their papers.

\section{The proposed research impact continuum}

In this paper, the proposed continuum is presented in three ways:

- in Table 1, I attach labels to the various ways in which my work has been used by others and allocate a position on the continuum to each of them;

- in Table 2, I offer a formal definition of each type of use;

- in the main text, I explain the continuum in detail and direct attention to specific examples of how my work has been cited and used, in order to illustrate the types. As Cooke (2003) observes, "abstractions are better understood through examples".

\subsection{Replication, concentration and extension}

At the highest end of the spectrum, the individual's work is integral to the research of one of their successors. Three possible scenarios are suggested:

- the later researcher seeks to replicate the original project in a new context and adheres to the characteristics of the original study as closely as possible when designing and carrying out their own (feature $a$ );

- a key outcome from the original project, such as a theory, model or typology, becomes the subject of the subsequent work (feature $b$ );

- the later researcher explicitly acknowledges the value of the earlier study, reports it in detail and explains that they expect to extend it (feature $c$ ).

In actual research situations, there may be a very close relationship between features $a$ and $b$. An inquirer intent on investigating a particular outcome from past work may well wish to repeat, in a new situation, the methodology adopted in the preceding study. This will not always be the case, however, since a new project may employ entirely different and even innovative approaches in order to find out more about the outcome involved. In any instances where the academic's paper is integral to the research that has followed, the answer to the question 
"Could the more recent study have taken place without the previous work?" should be a resounding "no".

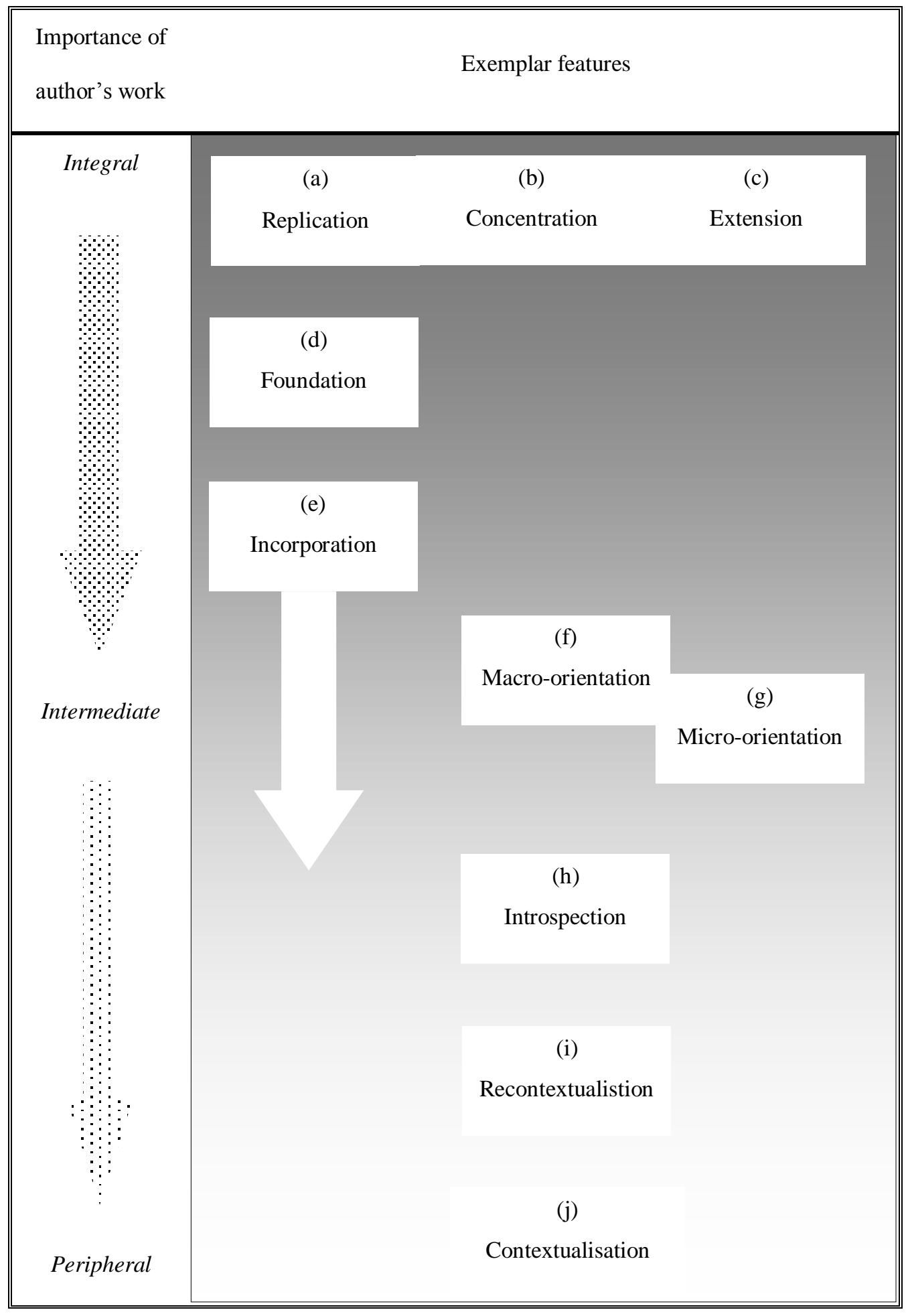

Table 1: The proposed grounded research impact continuum. 


\begin{tabular}{|c|c|c|}
\hline Feature & & Typical form \\
\hline (a) Replication & \multirow{10}{*}{$\begin{array}{c}\text { New } \\
\text { research... }\end{array}$} & repeats author's work in new context \\
\hline (b) Concentration & & adopts outcome from author's work as focus \\
\hline (c) Extension & & explicitly builds on author's work \\
\hline (d) Foundation & & uses author's definition(s) to establish underpinning concept(s) \\
\hline (e) Incorporation & & includes elements of author's work in key phase of study \\
\hline (f) Macro-orientation & & frames broad study territory within author's constructs \\
\hline (g) Micro-orientation & & places study specifics in terms of author's framework \\
\hline (h) Introspection & & draws on author's work as part of reflective assessment of project \\
\hline (i) Recontextualisation & & addresses author's work in retrospective literature review \\
\hline (j) Contextualisation & & covers author's work in advance literature review \\
\hline
\end{tabular}

Table 2: Explanation of impact factors within the continuum.

As replication involves restaging the original project with few significant changes, it provides the purest form of study-to-study repetition. The population under scrutiny may be altered; the physical location of the fieldwork may have shifted; the time at which data are collected will almost certainly be later but in virtually all other key respects the differences between the two projects will be no more than minor. In many kinds of research, however, replication of this kind is unusual. With regard to case studies, Gomm, Hammersley and Foster (2000) note that whilst it is possible for later research to build on a preceding project by providing additional cases that can be used to construct wider generalisations, in practice the subsequent cases:

are not usually selected in such a way as to complement previous work, and the research is often pursued in a manner that is sufficiently different to make comparison impossible.

(Gomm, Hammersley and Foster, 2000, 107)

\subsection{Contextualisation and recontextualisation}

At the lowest end of the spectrum, the original work is no more than peripheral to the new study. This is true, for example, where a paper has been cited in a wideranging literature review. In general terms, we may assume that the more authors are mentioned in the review, the more diluted the impact of the individual researcher, unless this individual is specifically flagged as one of the key authorities in the field. It is useful, however, to draw a distinction between advance literature reviews (feature $j$ ) and retrospective literature reviews (feature $i)$. In the case of the former, the material is used to establish the context of the study and to present the knowledge base. In the latter instance, the author revisits pertinent work having reported his or her own findings, seeking to understand 
these results in terms of a bigger picture, especially with regard to common patterns and differences emerging from the overall body of literature. The scale of the comparison may vary; it may range from assessing one whole model against another to the minute consideration of individual findings or observations. It may address a broad generalization, which has been made by an earlier researcher; in other instances, investigators may apply their own results to typologies proposed by others. Some discussions involving previous typologies are highly rigorous. Agosto and Hughes-Hassell (2006) assess each of the seven information need categories that they define in their own study against those in breakdowns presented in five previous projects, including Shenton and Dixon (2003a). The work of Walker is of particular interest, in that he draws on my ideas at varying levels. In terms of the minutiae of the behaviour of his individual participants, Walker (2010) indicates that one of them "reported behaviour similar" to that associated with Shenton's (2009) notion of "inferential information-seeking". More broadly, Walker $(2012,563)$ elsewhere notes how, in his study, the process of determining the relevance of the material people encounter "is often imprecise and certainly fits with the area of 'inferential information-seeking"'. In retrospective literature reviews, the impact of the original investigation may be deemed intermediate. The researcher has gone beyond merely stating the predecessor's findings at the outset but the new study could have taken place without the existence of the earlier project.

\subsection{Foundation}

Beyond almost complete replications, there are many instances where a new project incorporates significant elements of earlier inquiries. It is not uncommon for a researcher to formulate a particular definition of the phenomenon in question and to adhere to it in order to guide their subsequent investigation. By disclosing this premise to the reader of the report, the author also issues an unambiguous statement as to the boundaries of their study and the territory to be addressed. Moreover, those areas that have been deliberately excluded will be clearly apparent. Where a later researcher adopts this definition (feature $d$ ), "foundation" may be said to be evident. It should be stressed that for "foundation" to take place the later researcher must use their predecessor's definition to focus their own inquiry. The work of Davies (2013) provides an example of this. He declares unequivocally, "The present study adopts Shenton's (2004a) definition of information" (Davies, 2013, 20). Later in his thesis, Davies $(2013,44)$ refers to this construct as his "operational definition". If, however, the original author's definition is merely presented as one of several during a general discussion of the relevant concepts, this is scarcely different from reporting the findings of a previous project in a topic-oriented advance literature review.

\subsection{Incorporation}

With regard to study methods, it may be that the particular mode of questioning used with interviewees has been adopted (with slight adaptations) from a past study. Crow $(2011,6)$, for example, acknowledges that her "protocol for the second line of questioning (information seeking experiences) was developed by Shenton and Dixon (2003b)". This is an instance of significant "incorporation" 
(feature $e$ ) but in other situations the "borrowing" of ideas for use in the study method may be less fundamental. Henefer (2007) recounts that in her own project:

Provided with a list of information needs and information sources derived from previous surveys of young people's information needs and sources [which include Shenton (2002)], respondents were asked to indicate whether they had experienced any of these needs or consulted any of the sources during the past year.

(Henefer, 2007, 55)

Although the above instances refer to cases in which elements within earlier research are included in the data gathering phase of a later inquiry, as Table 2 indicates, the incorporated aspects may relate to any stage of the project. These may include, for example, data analysis or ways of reporting results.

\subsection{Macro-orientation and Micro-orientation}

The ripples of research may, of course, be apparent in later studies without any form of replication or incorporation at all. Instead, aspects of the new study may be seen in terms of concepts proposed by a predecessor. Features $f$ and $g$ provide two examples. In feature $f$, the broad territory of the new research is framed against constructs formulated by a previous author. For instance, Usherwood, Wilson and Bryson (2005) write:

Shenton and Dixon (2003b) illustrate that information seeking is essentially a convergent process involving the making of choices and taking of decisions. Information seeking is initiated when a situation arises which stimulates an information need, under which several types of information may be needed, including spontaneous 'life situation' information (such as a specific health concern), an empathic understanding of others and interestdriven information. The present study seeks to understand how museums, libraries and archives 'fit in' to the information seeking behaviours of the British public in pursuing such contemporary information needs and seeking a fuller understanding of contemporary concerns.

(Usherwood, Wilson and Bryson, 2005, 17)

Researchers may present contrasts between the concept at the heart of their research and related ideas proposed by others. Savolainen and Kari (2004), for example, detect a fundamental difference between Shenton and Dixon's (2003c) notion of an "information universe" and the concept of an "information horizon" upon which they choose to concentrate - the former would seem to them to be wider since it "does not merely encompass information sources but also the methods employed for their exploitation" (Savolainen and Kari, 2004, 417).

A lower level perspective on the earlier work is taken in feature $g$, meanwhile, with the new study relating individual foci of interest to those that the past researcher has highlighted.

\subsection{Introspection}

In feature $h$, new research exploits insights from previous work when making a reflective assessment of a particular aspect of the study, such as its design or 
recommendations. Let us consider two examples taken from different stages of projects. Discussing their decision to carry out their research in the school environment, Duffy, Liying and Ong (2010) comment:

This study was open to the same strengths and weaknesses identified by Shenton (2004b). He identifies administrative and contextual reasons among the benefits, and timing, permission and absenteeism among the weaknesses.

(Duffy, Liying and Ong, 2010)

In the second example, Large et al. (2009) conclude their report on the design of a prototype Web portal for children by observing:

Although the project's objective was to evaluate information visualization, it also casts light upon a conventional taxonomy design and suggests improvements that might be incorporated. For example, more than one level within the hierarchy could be displayed at any one time, although this would increase the scanning and reading challenge to young users (Shenton and Dixon, 2004).

(Large et al., 2009, 277-78)

Whilst, in many instances, a study that cites a particular project will exhibit only one of the features shown in Tables 1 and 2, it is entirely possible for several to be apparent within a single inquiry.

\section{Caveats}

Even within the confines of my own work, the spectrum presented here should not be assumed to be in any way comprehensive or totally authoritative. I have noted ten kinds of features associated with impact and placed them on a scale; there are no doubt others I could have identified and readers may disagree with the relative positions I have given to the individual features. Specific limitations of the spectrum include both the fact that it is based on the experiences of one particular academic, and that the interpretations which have been brought to bear are solely my own. There will probably be some readers who query the lowly placement of recontextualisation. In terms of her own area of interest, human-computer interaction, Borgman $(1986,47)$ argues that understanding is gained "in hard-won pieces, rather than through one grand experiment". If we accept this claim, we may take the line that, after completing their study, a researcher should assemble the existing relevant "pieces", including their own paper, and summarise what can be learnt from the totality. Where this is done, the previous work that is covered in the analysis is obviously of considerable importance, yet it is only in the closing stages of the project that it has become assimilated into the study. In some reports it may seem that the comparison has been "bolted on" almost as an afterthought.

Many readers will have encountered circumstances in which their study findings, or the arguments that they have used in their research for taking particular courses of action, have been cited by later writers in support of their own research decisions. Since positioning these situations on the impact continuum is often highly problematic, I have made no attempt here to do so and it would seem sensible to discuss such scenarios in isolation from the table showing the 
spectrum. On one hand, a case can be made that the original work is integral to the new study as it may appear that the predecessor's project has significantly affected the thinking of, and decisions taken by, the later investigator. The work of Gasser et al. (2012) provides a useful illustration of this. After reporting at some length the findings of Shenton, Nesset and Hayter (2008), who outline a wide range of ways in which young people may grasp the concept of "information", the authors conclude that it is not "ethnographically appropriate to... attempt a precise analytical definition of information" and it is preferable:

to allow variation in understanding of information. Thus, we fold various understandings of the word 'information' into the flexibility of [our] information quality framework.

(Gasser et al., 2012, 27).

It is possible, however, that the later writer has not been influenced at all by their predecessor. The subsequent researcher may have made up their mind as to their project's design before even reading the earlier paper and the reference may have been added at a later stage simply to strengthen the justification for employing the chosen method or taking the line that has been adopted.

\section{Use of a grounded research impact continuum}

I have assumed that after creating a continuum of the kind discussed in section four, the researcher will, most likely, present this spectrum, probably in diagrammatic or tabular form, with an accompanying commentary. They will have begun by creating a typology that shows the different ways in which later researchers have used the individual's work. Essentially, the researcher outlines through categories as many different forms of use as they have been able to identify and illustrates each with pertinent examples. The respective roles of the categories and examples in such a situation are well-explained by Lofland (1976):

the abstractions [taking the form of the categories] and qualitative data [which may here be understood to take the form of coverage of the particular instances] coexist as one whole. Each depends on the other for enlightenment and meaning. Taken separately, the abstractions and data may have slight interest or merit. The abstractions are likely to be dull because the reader has an inadequate conception of the concrete, empirical reality to which they might refer. The qualitative data alone are dull because the reader has little notion of generic patterns involved, save those he might himself be imposing. But interpenetration through minute and continual alternation between abstraction and episodes makes the whole more than the parts.

(Lofland, 1976, 65)

Once the individual has identified as many different kinds of use as possible, they can rank these according to their own integral-intermediate - peripheral spectrum and retain this order when writing up their analysis.

An alternative approach involves presenting mini-case studies, which, in their totality, cover in detail a small number of different situations where the individual's work has been used. The reporting is likely to incorporate at least 
some background description of the projects citing the research, in order to ensure that the reader can appreciate the particular contexts in which the older work has been cited. If a continuum is created, the researcher may then choose to report as case studies instances of use that lie in the integral or integral-to-intermediate part of the spectrum.

Ostensibly, it may seem attractive to combine statistical and typological elements, with the researcher attaching frequencies to each of the categories within the typology. In practice, however, this strategy is difficult to implement. Whilst it may be easy to collect statistics relating to the number of times a particular paper has been cited overall, it is a much more challenging task to obtain copies of each of the citing publications with a view to identifying how the source material has been employed and then to generate appropriate individual frequency counts.

\section{Conclusion}

Drawing on my experiences as a recent candidate for a higher doctorate at Northumbria University, I began this paper from the perspective that statistics stating the frequency with which a particular paper has been cited are a blunt instrument, and they give insufficient insight into the nature of the use that has been made of the work. I have proposed for consideration the development of a grounded research impact continuum. This places on a descending scale the ways in which new studies draw on past work. The scale's extremities denote situations where the cited material is either integral or no more than peripheral to the new work. This type of continuum can be employed in two different ways, either to sequence categories of use within a typology or as an aid to help the researcher to select the most powerful stories to tell in mini-case studies. Some readers may welcome this approach on the basis that it provides a more vivid insight into the use of research than dry statistics offer. Certainly, it can be tailored more precisely to the specific citations of the researcher's work than could be achieved by using an existing framework. However, only time will tell whether it comes to form a useful tool in the armoury of methods that may be exploited by researchers looking to demonstrate the impact of their work.

\section{References}

Agosto, D.E. and Hughes-Hassell, S. (2006) Toward a model of the everyday life information needs of urban teenagers, part 2: empirical model, Journal of the American Society for Information Science and Technology, 57(11), 1418-1426.

Aldhous, P. (2009) CRAP paper accepted by journal, New Scientist: Opinion, 28 September 2008. URL: http://www.newscientist.com/article/dn17288-crap-paperaccepted-by-journal.html\#.VGHHjKFFAd [accessed 12.11.2014].

Barnes, T. (2013) Higher doctorates in the UK 2013. Lichfield: UK Council for Graduate Education. URL: http://www.ukcge.ac.uk/pdf/Higher\%20Doctorates\%20in\%20the\%20UK\%20201 3\%20Bookpdf.pdf [accessed 12.11.2014]. 
Borgman, C.L. (1986) The user's mental model of an information retrieval system: an experiment on a prototype online catalog, International Journal of Man-Machine Studies, 24(1), 47-64.

Chubin, D.E. and Moitra, S.D. (1975) Content analysis of references: adjunct or alternative to citation counting? Social Studies of Science, 5(4), 423-441.

Cooke, A. (2003) Letter from America: I am a jelly doughnut, BBC Radio 4, 3 October. URL: http://www.bbc.co.uk/programmes/p00spzq7/features/transcript [accessed 12.11.2014].

Crow, S.R. (2011) Exploring the experiences of upper elementary school children who are intrinsically motivated to seek information, School Library Research [online], 14. URL:

http://www.ala.org/aasl/sites/ala.org.aasl/files/content/aaslpubsandjournals/slr/vol 14/SLR_ExploringtheExperiences_V14.pdf [accessed 12.11.2014].

Davies, R. (2013) Towards a model of information behaviour of an information provider: a mixed methods study. PhD thesis, Robert Gordon University, Aberdeen.

Duffy, A., Liying T. and Ong, L. (2010) Singapore teens' perceived ownership of online sources and credibility, First Monday [online], 15(4). URL:

http://firstmonday.org/htbin/cgiwrap/bin/ojs/index.php/fm/article/view/2197/2484 [accessed 12.11.2014].

Gasser, U., Cortesi, S., Malik, M. and Lee, A. (2012) Youth and digital media: from credibility to information quality. Cambridge, Massachusetts: Berkman Center for Internet and Society, Harvard University. URL:

http://dmlcentral.net/sites/dmlcentral/files/resource files/ssrn-id2005272.pdf [accessed 12.11.2014].

Gomm, R., Hammersley, M. and Foster, P. (2000) Case study and generalization. In: Gomm, R., Hammersley, M. and Foster, P. (eds.) Case study method. London: Sage. 98-115.

Harzing, A.W. (2011) The publish or perish book: your guide to effective and responsible citation analysis. Melbourne: Tarma Software Research.

Henefer, J. (2007) "Not that I wouldn't trust them, I trust probably two of them..." Exploring the information worlds of ethnic minority adolescents in Ireland, Youth Studies Ireland, 2(2), 50-67. URL:

http://youthworkireland.ie/images/uploads/general/Not_that_I_wouldnt_trust the m.pdf [accessed 12.11.2014].

Large, A., Beheshti, J., Clement, I., Tabatabaei, N. and Tam, M.T.Y. (2009) Visualizing a hierarchical taxonomy in a children's Web portal: user evaluations of a prototype, Canadian Journal of Information and Library Science, 33(3/4), 255-282.

Lofland, J. (1976) Doing social life: the qualitative study of human interaction in natural settings. London: John Wiley and Sons.

Marsh, R. (2010) Measuring the impact of research, Library Review, 59(1), 74-75. 
Moravcsik, M. J. and Murugesan, P. (1975) Some results of the function and quality of citations, Social Studies of Science, 5(1), 86-92.

Sarli, C.C., Dubinsky, E.K. and Holmes, K.L. (2010) Beyond citation analysis: a model for assessment of research impact, Journal of the Medical Library Association, 98(1). URL: http://www.ncbi.nlm.nih.gov/pmc/articles/PMC2801963/ [accessed 12.11.2014].

Savolainen R. and Kari, J. (2004) Placing the Internet in information source horizons: a study of information seeking by Internet users in the context of selfdevelopment, Library and Information Science Research, 26(4), 415-433.

Shaw, C. (2013) Hundreds of open access journals accept fake science paper. Guardian Professional, 4 October. URL: http://www.theguardian.com/highereducation-network/2013/oct/04/open-access-journals-fake-paper [accessed 12.11.2014].

Shenton, A.K. (2002) The characteristics and development of young people's information universes. PhD thesis, Northumbria University, Newcastle upon Tyne.

Shenton, A.K. (2004a) Operationalising the concept of "information" for research into information behaviour, Aslib Proceedings, 56(6), 367-372.

Shenton, A.K. (2004b) Information-seeking research in schools: opportunities and pitfalls, Aslib Proceedings, 56(3), 180-186.

Shenton, A.K. (2009) Inferential information-seeking, Library Review, 58(5), 353-361.

Shenton, A.K. (2014) Demonstrating personal stature: some strategies for the LIS higher doctoral candidate, Library Review, 63(8/9), 590-605.

Shenton, A.K. and Dixon, P. (2003a) Youngsters' use of other people as an information-seeking method, Journal of Librarianship and Information Science, 35(4), 219-233.

Shenton, A.K. and Dixon, P. (2003b) Models of young people's information seeking, Journal of Librarianship and Information Science, 35(1), 5-22.

Shenton A.K. and Dixon, P. (2003c) A comparison of youngsters' use of CDROM and the Internet as information resources, Journal of the American Society for Information Science and Technology, 54(11), 1029-1049.

Shenton, A.K. and Dixon, P. (2004) How do youngsters use public libraries to find non-fiction books? The results of a recent research project, Public Library Quarterly, 23(3/4), 77-98.

Shenton, A.K., Nesset, V. and Hayter, S. (2008) Children's conceptualizations of the word, "information", Journal of Librarianship and Information Science, 40(3), 151-164.

Usherwood, B., Wilson, K. and Bryson, J. (2005) Relevant repositories of public knowledge? Perceptions of archives, libraries and museums in modern Britain. Sheffield: Centre for the Public Library and Information in Society, Department of Information Studies, University of Sheffield. URL: 
https://www.shef.ac.uk/polopoly fs/1.128102!/file/CPLIS---Repositories-ofPublic-Knowledge.pdf [accessed 12.11.2014].

Walker, C. (2012) The information world of parents: a study of the use and understanding of information by parents of young children, Library Trends, 60 (3), 546-568.

Walker, C.G. (2010) The information world of parents: a study of the use and understanding of information by parents of primary school aged children. $\mathrm{PhD}$ thesis, Leeds Metropolitan University, Leeds.

Wilson, T.D. (1996) Monitoring and evaluating information-related research, Education for Information, 14(2), 85-93.

\section{Open access and copyright}

Library and Information Research is an open access journal. A freely available copy of this paper may be downloaded from the journal's website:

http://www.lirgjournal.org.uk.

Copyright and associated moral rights in works published in Library and Information Research are retained by the author(s) but this paper may be used freely, with proper attribution, in educational and other non-commercial settings. 